\title{
PRODUCTION EFFICIENCY EVALUATION AND PRODUCTS' QUALITY IMPROVEMENT USING SIMULATION
}

\author{
Kliment, M.; Trebuna, P.; Pekarcikova, M.; Straka, M.; Trojan, J. \& Duda, R. \\ Technical University of Kosice, Faculty of Mechanical Engineering, Institute of Management, \\ Industrial and Digital Engineering, Park Komenského 9, 04200 Kosice, Slovakia \\ E-Mail: marek.kliment@tuke.sk, peter.trebuna@tuke.sk,miriam.pekarcikova@tuke.sk, \\ martin.straka@tuke.sk,jozef.trojan@tuke.sk,richard.duda@tuke.sk
}

\begin{abstract}
Every manufacturing company producing products of any kind is forced to constantly address the issue of improving the efficiency of its production lines, increasing their production capacity and last but not least, increasing the quality of products. Every physical intervention directly in the production process results in a change in the efficiency of this process. It may be a change for the better, but often such a change may not have the expected effect. Today's era of digital industrialization offers us the opportunity to verify possible changes in the production process without physically interfering with existing production, and thus it is also possible to verify the real consequences of the intervention. The present paper deals with improving the efficiency and quality of products in the production process in the food industry. It is the production of various types of packaged salads, cod and other types of fish. The aim of the paper is to test the possibility of improving the efficiency of the packaging line for food products as well as the possibility to improve their quality by applying sensors of foreign bodies of various kinds, which can sometimes get into salads.

(Received in June 2020, accepted in August 2020. This paper was with the authors 2 weeks for 2 revisions.)
\end{abstract}

Key Words: Simulation, Production Process, Efficiency, Quality

\section{INTRODUCTION}

In the $21^{\text {st }}$ century, most of the world's successful companies and firms use various simulation programs to design production. These programs make it possible to observe the entire production process with the smallest details, while the simulation can be stopped at any time and restarted. Careful monitoring of the simulation can reveal bottlenecks, errors and various shortcomings that could arise in real production [1]. If production is well mapped and there is no access to it at any time and it is necessary to take an unbiased view of improvement in it, simulation is a very good solution. In addition, it can be stopped and started at any point, and a change can be made at any point, which can then be validated with the actual state based on various technologies. It is thus possible to provide the production organization with a presentation of possible changes in the existing production process, or to provide it with suggestions for its improvement in the event of a certain change in production parameters. In some cases, these are small changes that may not be very costly for the organization, but in some cases, optimization solutions require investments with a longer payback period. With the help of simulation programs, it is possible to ensure that before the start of real production, it is clear that the production will be without any errors, downtime and maximally efficient. Whole production systems can be subjected to simulation. In this paper, the simulation software Tecnomatix Plant Simulation will be used for the realization of the simulation. Therefore, it is necessary to define the terms production system and approach some of the possibilities of this software $[2,3]$.

The production system model shown in Fig. 1 usually consists of these objects:

- Static permanent objects (non-moving elements of the system acting permanently warehouses, machines, etc.). 
- Dynamic temporary objects (moving elements entering the system, which move between the static elements of the system and leave the system at some point - components, pallets).

- Elements of connection with the environment (locations where dynamic objects enter the system and leave the system at the same time) [4].

After testing the model, experiments are started to search for various alternatives for system improvement and to determine their impact on the modelled system. Simulation is not a program with which it is possible to directly obtain the optimal solution. It is used as a support tool to help the designer test the effects of his decisions on a simulation model $[5,6]$.

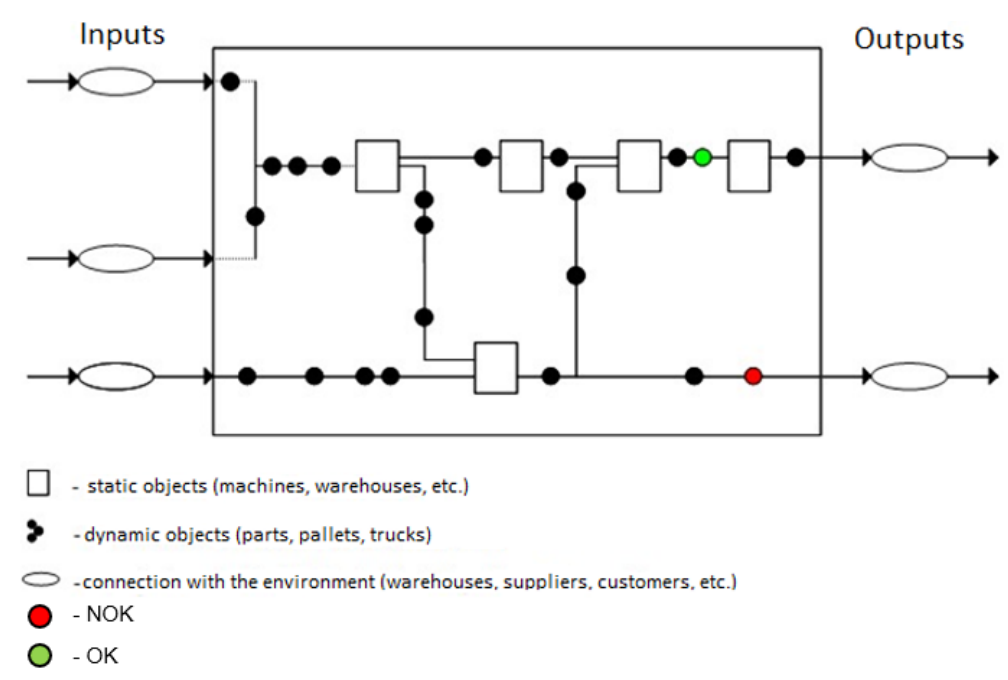

Figure 1: Model of production system.

Tecnomatix Plant Simulation provides an environment for creating simulations. Using Plant Simulation, it is possible to optimize material flow, resource utilization and logistics at all levels of plant planning, from global production facilities, through local plants to specific lines [7]. In times of rising costs and time pressures in production along with continuing globalization, logistics has become a key factor in the company's success. The need to deliver on time and gradually, implement lean manufacturing principles, plan and build new sustainable production facilities, and manage global production networks requires objective decision criteria to help management evaluate and compare alternative approaches. The simulation makes it possible to create a digital model of the logistics systems plant so that authorized employees can monitor the properties of the system and optimize their performance. The digital model can be implemented in the planning process long before the actual system is started. Plant Simulation software provides extensive analytical tools, graphs, and statistics to help users evaluate various production processes and take quick and reliable steps in the early stages of production planning [8-10].

\subsection{Modelling of production processes}

Plant simulation allows companies to create well-structured hierarchical models of production equipment, lines and processes. This is achieved through powerful object-oriented architectures and modelling capabilities that enable customers to create and maintain highly complex systems, including advanced control mechanisms. The intuitive, context-sensitive Plant Simulation ribbon user interface follows Microsoft Windows standards, making it easy to get to know and work quickly. Simulation models can be created quickly using components from application object libraries designed for specific business processes, such as manufacturing or car body manufacturing processes. Users can choose from predefined sources, order lists, operation plans, and control rules. Extending the library with company-specific objects allows 
the capture of proven technical experience for further simulation studies. Complex and detailed simulations can be manipulated, understood and maintained much better than in conventional simulation tools with the architectural advantages of Plant Simulation [11,12].

\subsection{Elimination of bottlenecks}

Plant Simulation models are used to streamline throughput, reduce bottlenecks, and minimize work-in-progress. Graphical outputs for automatic bottleneck detection, throughput analysis, machine, resource and buffer utilization, Sankey diagrams and Gantt charts are among the many tools available to evaluate the performance of your production systems. Simulation models take into account internal and external supply chains, production resources, and business processes, allowing you to dynamically analyse the impact of different production variations $[13,14]$.

\subsection{Practically put the production systems into operation}

Tecnomatix Plant Simulation allows the virtual device model to be linked to actual plant management, thereby simulating actual production. With this integrated simulation approach, it is possible to test and optimize control, automation, material transport and the entire technical operation. It is possible to connect either a virtual (software) programmable logic controller (PLC) or a real (hardware) PLC from a real environment. This commissioning is flexible and open and can be used in conjunction with any PLC $[15,16]$.

\subsection{Benefits}

Plant simulation helps manufacturers:

- Identify and eliminate problems that would otherwise require costs and time-consuming corrective action during the production ramp.

- Reduction of investment costs that could arise in reality.

- Optimize the production process in a simulation environment before implementation in real production.

- Elimination of bottlenecks and increased use of production resources [17, 18].

Accurate digital modelling, simulation and spatial (3D) visualization allow to visualize and analyse the future production process, thus limiting the possibility of errors that could occur during the start of production, but also during its normal operation [19-21].

\section{PRODUCTION PROCESS ANALYSIS}

\subsection{Problems of production process}

A similar proposal to streamline the production process has been addressed in the company for the production of various second salads and other fish products and various other raw materials. The aim of streamlining the production process was to meet two factors:

1. One major customer of the company requires that products sold under its brand be inspected for the presence of undesirable bodies, such as: metals, plastics and glass, which have been found in a small number of products from another supplier. The presence of such bodies in the products is very unlikely. All raw materials added to the products are already checked in the previous steps of production, however, without such a check it can never be completely ruled out that nothing undesirable can get into the product during the production process. In this way, this customer tries to avoid losing their customers and damaging the good name of their retail chain. This serious error in the production process can lead to consequent damage to the health of end customers who could consume the product with such a body. The company in question is therefore forced to inspect the products it manufactures for that 
customer under its trade mark by means of a separate detector for such elements, which considerably prolongs the production process, since such inspection requires a considerable time to inspect all the products required by that customer (Fig. 2).

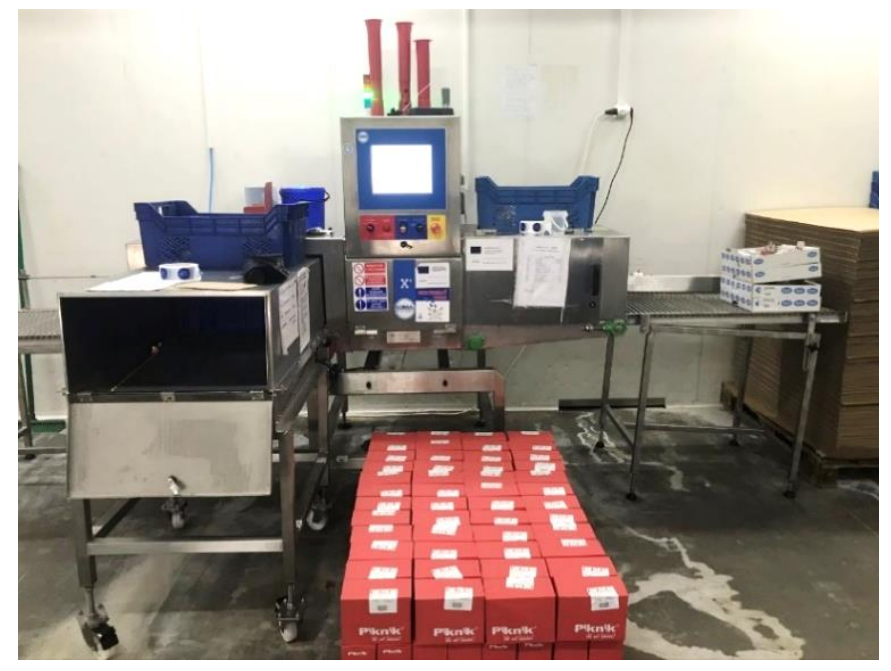

Figure 2: Product inspection detector to prevent the presence of unwanted bodies.

2. The manufacturing company plans to introduce automation elements into the packaging of its products and to reduce both the manual burden on workers and to ensure a larger volume of packaged products on its packaging lines. With this step, it wants to improve the production process and ensure its greater efficiency.

\subsection{Description of the production process of selected types of products}

The company's production program covers a wide range of products. Its assortment includes more than 400 types of various food products. Today's product assortment is presented by two of its own range of branded brands. It holds a certificate confirming the implementation and use of the quality management system according to EN ISO 22000: 2005. It also has an established HACCP system, which ensures the quality and health safety of the entire production process. Tests are performed daily in our own laboratory. At the same time, permanent veterinary supervision is established. The quality of the products is also evidenced by several SLOVAK GOLD awards. The production of the entire assortment takes place on two floors in a separate production hall.

It would be very difficult to solve the optimization of the entire range of production. As a model for solving suggestions for improvement, one type of products was selected, which is significantly represented in the assortment and is among the best-selling in the entire production. The production of Cod was selected. A diagram of the manufacturing process is shown in Fig. 3 and is described below.

\subsection{Course of Cod production in mayonnaise}

The Cod production process begins with the receipt of frozen fish from storage. Prior to processing, the frozen fish raw material is unpacked from the transport packaging and stored in a thawing box, where the thawing process itself takes place. Thawing takes place in the afternoon and at night. Thawing time is 15 to 24 hours. At the end of the thawing process, the raw material is unwrapped from the foils and at the same time the quality of the thawed raw material is checked. Another process is cooking in cooking chambers, which lasts approximately 90 minutes. After cooking, the raw material is cooled by air in a cooling chamber for about 30 to 45 minutes. The cooked fish is then cooled with water for about 30 to 45 minutes. 


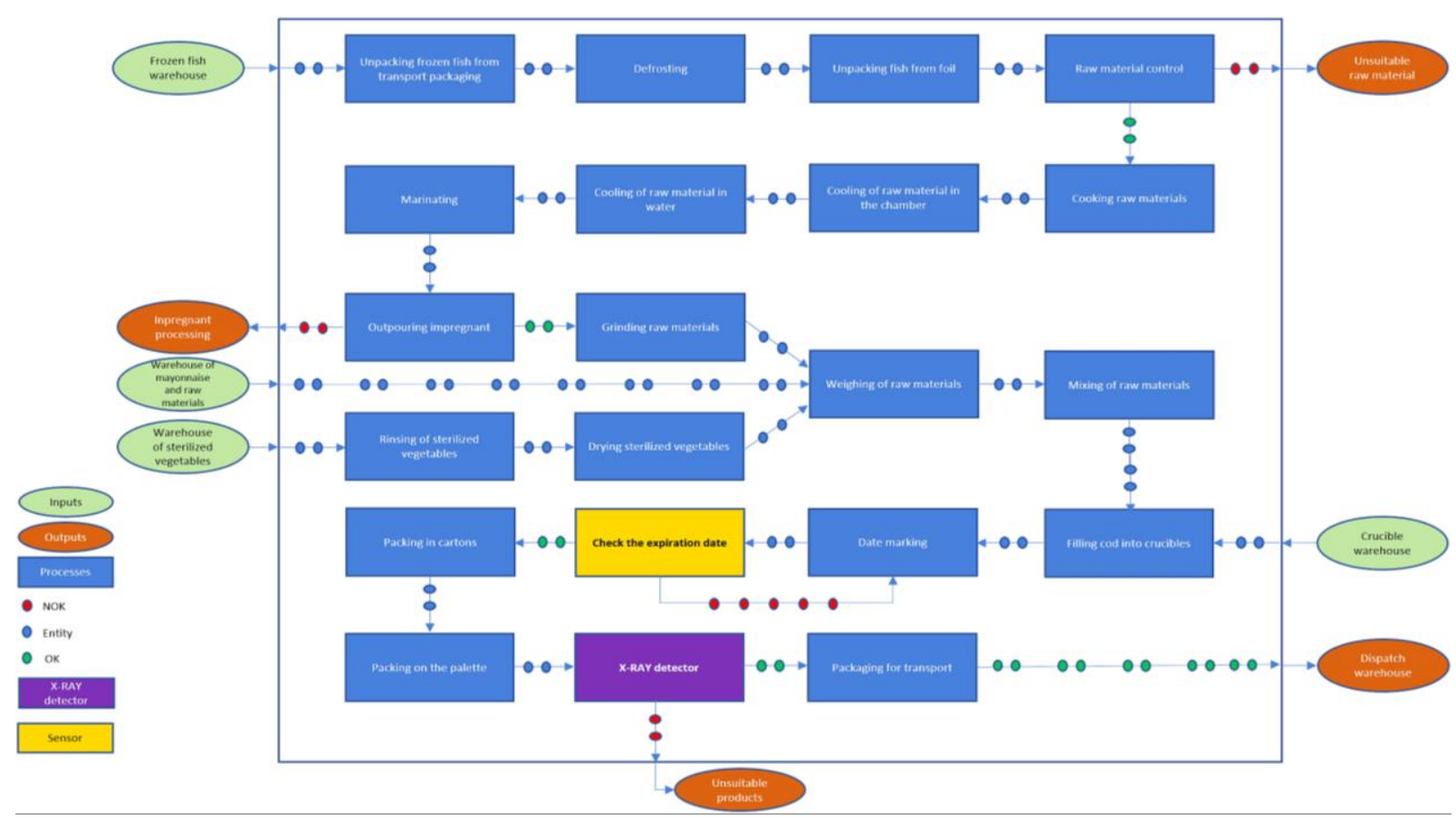

Figure 3: Diagram of the cod production process.

The cooled cooked fish raw material is moved to a marinating process, which takes 12 to 15 hours. At the end of the marinating period, the varnish is drained and then the raw material is cut on a grinder. The semi-finished product processed in this way is ready for the production of Cod. Another process is the preparation of sterilized vegetables, which must be rinsed and then drained for at least 5 minutes after being poured into sieve containers. Other necessary semi-finished products such as mayonnaise are prepared in advance and stored in their place, from where the expected volume is transferred for the given day for weighing. Other additives are weighed according to the material standard and are added when weighing the mixture into Cod. After weighing the individual semi-finished products and additives, the container is moved to the production room, where the penultimate phase of production takes place. The weighed mixture is poured into a mixing machine and the mixed Cod mixture is then transferred to a hopper. The mixture from the hopper is gradually transferred to the machine and the Cod itself is filled into pre-marked plastic cups.

The machine will mark the correct expiration date. The products are then moved along the conveyor to the packaging process. There is a sensor on this conveyor that scans the entire product. This sensor checks whether the date of minimum consumption is correctly printed on the crucible (in Fig. 3 it is marked in yellow). If the date is not printed on the packaging, the sensor automatically discards this product using a flap in the hopper by the conveyor. The operator then returns these products to the marking device to indicate the date of minimum consumption.

The worker packs the required number of 16 pieces of products in a paper carton and places them on a pallet. As for the products for the above-mentioned customer, who additionally requires control for the presence of unwanted bodies, the entire pallet with products is moved to a free-standing detector (Fig. 2). All products packed in a cardboard box are gradually inspected on this detector. This check is performed by a worker who gradually takes cartons of products from the pallet and inserts them into the detector. If the detector detects unwanted particles, the entire carton is automatically discarded. Cartons, which are in order, are placed back on the pallet by the worker, and the worker proceeds to wrap the pallet with foil for safe transport of products to the dispatch warehouse, from where they are gradually delivered according to orders to branches and customers. 


\section{DIGITIZATION OF THE PRODUCTION PROCESS}

After the whole production process of the product was mapped, analysed and described its necessary properties, a digital model of this production was created. As already mentioned, the production takes place in the company on two floors, on which the individual production operations take place. In order to be able to capture the entire production process on both floors and link it into one simulation, it is necessary to use Frames when creating a simulation model. In each Frame, all necessary operations on a given floor are modelled and these Frames are interconnected (Fig. 4).

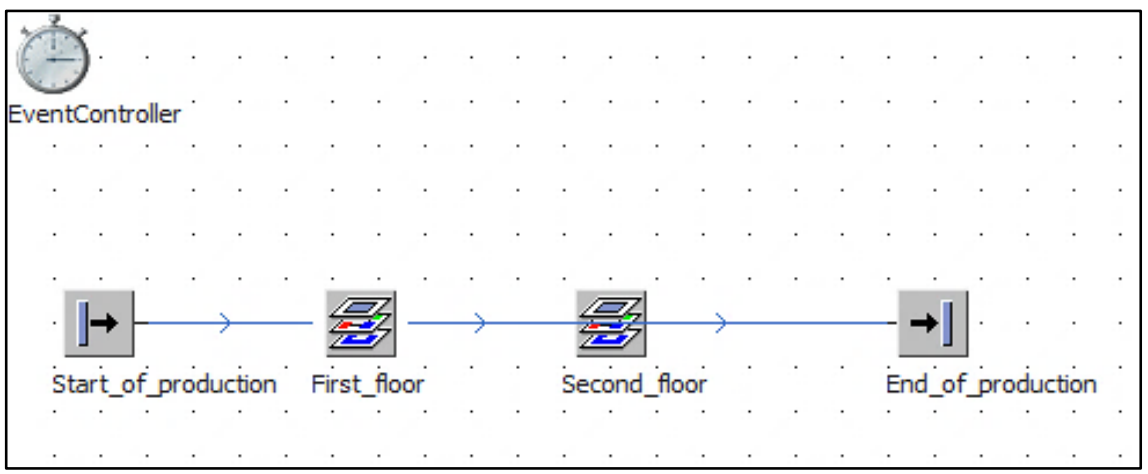

Figure 4: Production modelling using frames.

After clicking on the individual Frames, the modelled individual floors of the production hall will be displayed (Fig. 5).

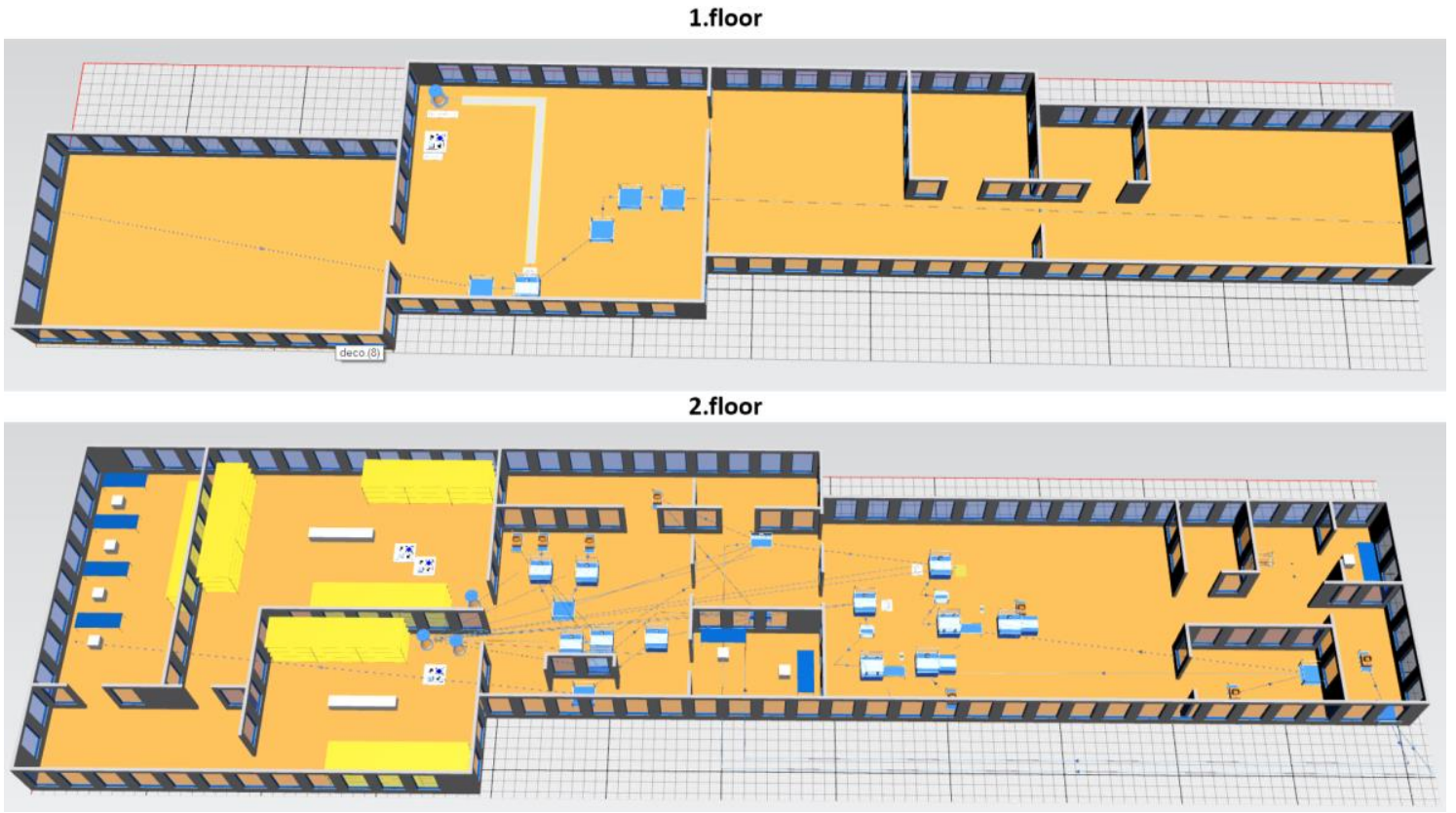

Figure 5: Models of individual floors in the 3D environment Tecnomatix Plant Simulation.

In the production space on both floors, the production of other products from the company's assortment takes place. The simulation model, however, was created only for a selected representative product. Fig. 5 shows the production model in its original form as it takes place today. This model captures the normal manufacturing process, for regular customers. This model does not include the above-mentioned inspection of products for the possible presence of foreign objects. It does not contain the aforementioned optimization in the packaging process. In this simulation model, the packaging is performed manually with the help of a 
worker, who transfers each package of the product manually and places it in a carton on a pallet (Fig. 6). After filling, this pallet leaves the production hall directly to the dispatch warehouse.

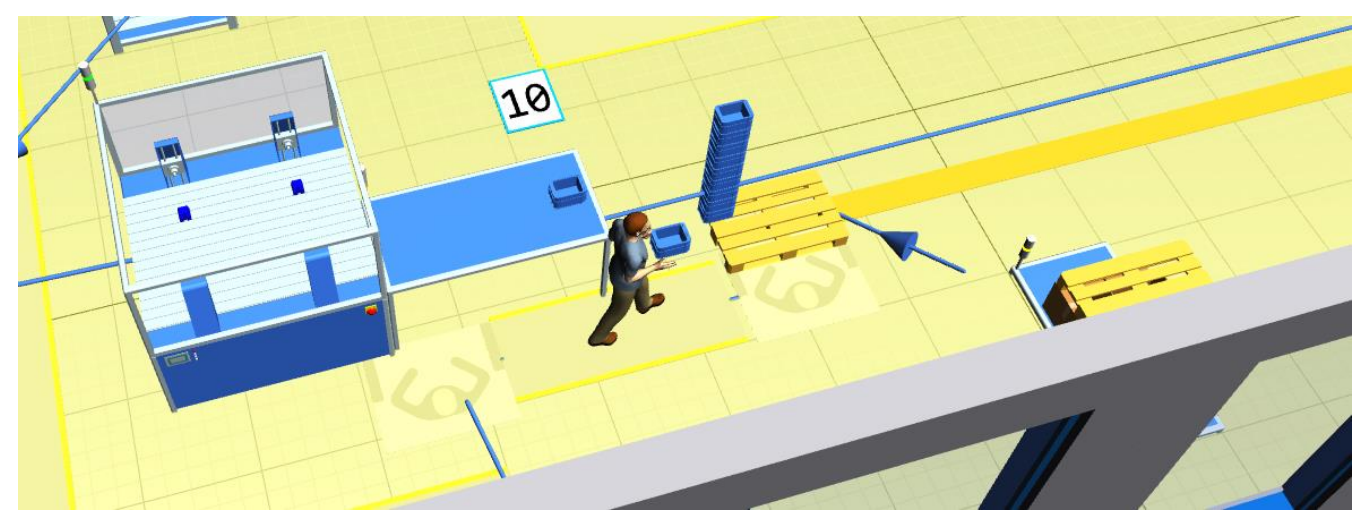

Figure 6: Manual packaging process.

Fig. 7 shows a statistical evaluation of such a production process in the normal and previous state. Statistics on basic indicators were taken from the software, such as: Productivity of the production process, which is at the level of $46.15 \%$ in this process. it is also possible to monitor data on how many individual devices have been in working mode, how long they have been blocked by other related operations, or how long they have waited for the operation to be completed before them.

\begin{tabular}{|c|c|c|c|c|c|c|c|c|c|c|c|c|}
\hline \multicolumn{13}{|c|}{ Cumulated Statistics of the Parts which the Drain Deleted } \\
\hline Object & Name & \multicolumn{2}{|c|}{ Mean Life Time } & \multicolumn{2}{|c|}{ Throughput } & $\mathrm{TPH}$ & \multicolumn{2}{|c|}{\begin{tabular}{|l|l|} 
Production \\
\end{tabular}} & \multicolumn{2}{|c|}{ Transport } & \multirow{2}{*}{\begin{tabular}{|r|} 
Storage \\
$0.00 \%$ \\
\end{tabular}} & \multirow{2}{*}{\begin{tabular}{|r|} 
Value added \\
$0.00 \%$ \\
\end{tabular}} \\
\hline End_of_production & Pallete_of_cod & 1:59: & 01.0441 & & 7 & 1 & & $15 \%$ & & $85 \%$ & & \\
\hline & \multicolumn{2}{|c|}{ Object } & \multicolumn{2}{|c|}{\begin{tabular}{|l|l} 
Working & s \\
\end{tabular}} & Set-up & \multicolumn{2}{|c|}{ Waiting } & \multicolumn{2}{|c|}{ Blocked } & \multicolumn{3}{|c|}{ Portion } \\
\hline & \multicolumn{2}{|c|}{ Cod_decantation } & \multicolumn{2}{|c|}{$51.00 \%$} & $0.00 \%$ & \multicolumn{2}{|c|}{$0.00 \%$} & \multicolumn{2}{|c|}{$49.00 \%$} & \multicolumn{3}{|c|}{+2} \\
\hline & \multicolumn{2}{|c|}{ Weighing_of_cod } & \multicolumn{2}{|c|}{$6.25 \%$} & $0.00 \%$ & \multicolumn{2}{|c|}{$62.06 \%$} & \multicolumn{2}{|c|}{$31.69 \%$} & \multicolumn{3}{|l|}{ 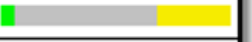 } \\
\hline & \multicolumn{2}{|c|}{ Mixing_of_cod } & \multicolumn{2}{|c|}{$15.63 \%$} & $0.00 \%$ & \multicolumn{2}{|c|}{$9.01 \%$} & \multicolumn{2}{|c|}{$75.36 \%$} & \multicolumn{3}{|c|}{ 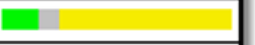 } \\
\hline & \multicolumn{2}{|l|}{ Cod_tray } & \multicolumn{2}{|c|}{$0.15 \%$} & $0.00 \%$ & \multicolumn{2}{|c|}{$5.93 \%$} & \multicolumn{2}{|c|}{$93.92 \%$} & \multicolumn{3}{|l|}{ 正 } \\
\hline & \multicolumn{2}{|l|}{ DS_2500 } & \multicolumn{2}{|c|}{$33.41 \%$} & $0.00 \%$ & \multicolumn{2}{|c|}{$5.94 \%$} & \multicolumn{2}{|c|}{$60.65 \%$} & \multicolumn{3}{|l|}{ b } \\
\hline & Packaging_c & of_cod & 50.00 & & $0.00 \%$ & & $0.00 \%$ & & $.00 \%$ & 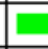 & & \\
\hline & Palletizing_C & of_cod & 55.53 & & $0.00 \%$ & & $4.47 \%$ & & $.00 \%$ & & & \\
\hline
\end{tabular}

Figure 7: Statistics of the current production process.

\subsection{Production process when performing an inspection using an X-Ray detector}

It was mentioned above that one of the major customers requires, in addition to quality controls, health safety, hygiene inspections and regular audits related to individual production standards, in addition to preventive inspection of all food products for the possible presence of undesirable objects such as metals, plastics, glass and the like. The company performs such a check on a device called an X-Ray detector. There are several disadvantages to performing such an inspection. One of them is that this device is located outside the production hall, where the packaging and production of products takes place, and therefore the handling and transport of products between production and this device is necessary. This means that the products, as already mentioned, are packed in cartons in the required number of pieces in the production hall, these cartons are placed on top of each other on a pallet and the products are moved to the X-Ray detector (Fig. 8). With this device, there must be an operator who gradually inserts cartons with packaged products into the device. If the products are in order, the carton is stored on another pallet and after its filling, the entire pallet is packed and forwarded to the dispatch warehouse. Such inspection of each packaged carton takes time, thereby reducing productivity 
and the number of products that production can dispense as finished products in a given shift. Another disadvantage is that 16 packages of the product are packed in one carton, and if an unwanted body is detected in such a package, the whole package is considered unsatisfactory. This means that if there is only one product unsuitable for export in a carton, the whole package is discarded.

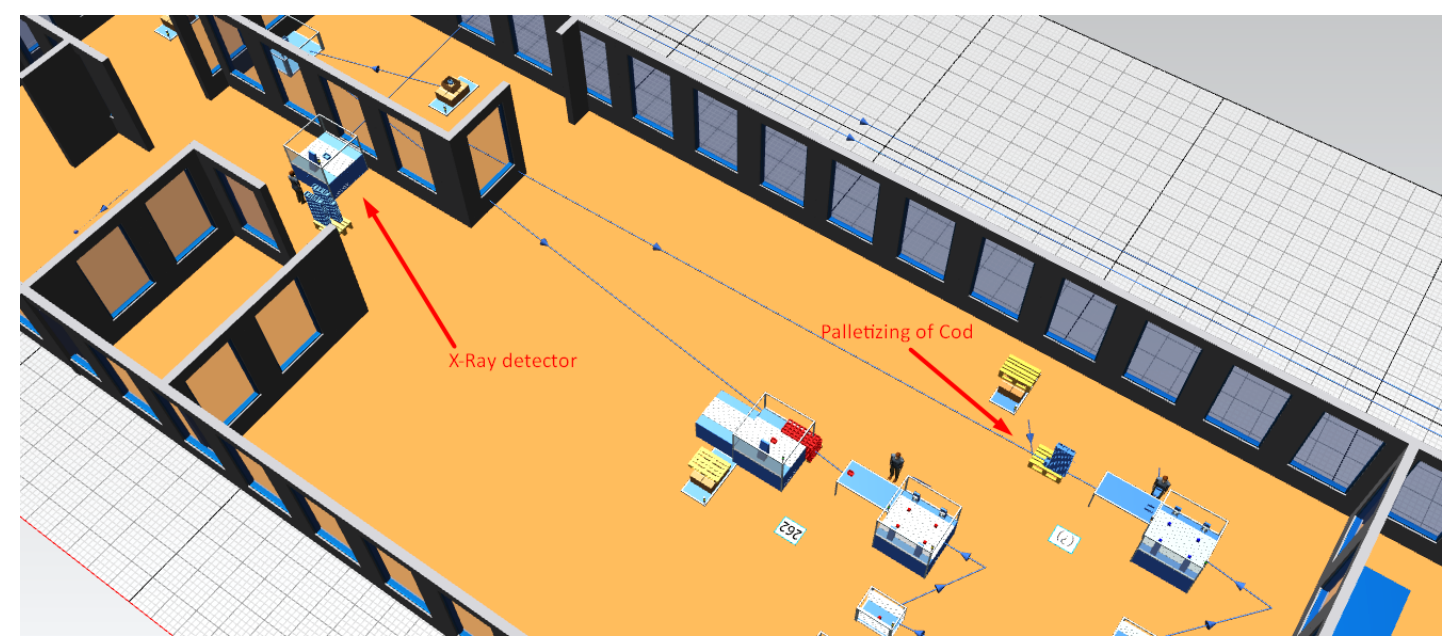

Figure 8: Location of the X-Ray detector in the production hall.

A significant decrease in production productivity with such a method of control can also be seen in the statistical evaluation offered by the Tecnomatix Plant Simulation software (Fig. 9). The productivity of such a production process is $19.03 \%$, which is a significant decrease compared to the original state. As a result, the complexity of fulfilling orders for this customer also increases. In addition, such a production process must involve another worker who operates the inspection equipment and ensures that the products are packed back on the pallet. On the contrary, an increase in the percentage of product transport after the production process is visible. From the original $53.85 \%$ transport increased to $80.97 \%$. Thus, when we compare the decrease in productivity of the production process with the increase in transport, we get to values of approximately $29.3 \%$, which is a significant deterioration of the indicators.

\begin{tabular}{|c|c|c|r|r|r|r|r|r|c|}
\hline \multicolumn{8}{|c|}{ Cumulated Statistics of the Parts which the Drain Deleted } \\
\hline Object & Name & Mean Life Time & Throughput & TPH & Production & Transport & Storage & Value added & Portion \\
\hline End_of_production & Pallete_of_cod & $4: 39: 41.8999$ & 5 & 1 & $19.03 \%$ & $80.97 \%$ & $0.00 \%$ & $0.00 \%$ & \\
\hline
\end{tabular}

\begin{tabular}{|l|r|r|r|r|c|}
\hline \multicolumn{1}{|c|}{ Object } & Working & Set-up & Waiting & Blocked & Portion \\
\hline Cod_decantation & $51.00 \%$ & $0.00 \%$ & $0.00 \%$ & $49.00 \%$ & \\
\hline Grinding_of_cod & $69.88 \%$ & $0.00 \%$ & $0.05 \%$ & $30.06 \%$ & \\
\hline Weighing_of_cod & $6.25 \%$ & $0.00 \%$ & $62.06 \%$ & $31.69 \%$ & \\
\hline Mixing_of_cod & $15.63 \%$ & $0.00 \%$ & $9.01 \%$ & $75.36 \%$ & \\
\hline Cod_tray & $0.15 \%$ & $0.00 \%$ & $5.93 \%$ & $93.92 \%$ & \\
\hline DS_2500 & $33.41 \%$ & $0.00 \%$ & $5.94 \%$ & $60.65 \%$ & \\
\hline Packaging_of_cod & $50.00 \%$ & $0.00 \%$ & $50.00 \%$ & $0.00 \%$ & \\
\hline Palletizing_of_cod & $55.53 \%$ & $0.00 \%$ & $44.47 \%$ & $0.00 \%$ & \\
\hline X_ray_detector & $51.28 \%$ & $0.00 \%$ & $18.60 \%$ & $30.11 \%$ & \\
\hline
\end{tabular}

Figure 9: Statistical evaluation of production using X-Ray detector.

\section{PROPOSAL FOR STREAMLINING THE PRODUCTION PROCESS}

As mentioned in the introduction to the article, the company is considering investing in improving part of the production process. First of all, it would like to optimize the process of 
inspecting its products and increase their quality for all its customers, not just for the said customer, for whom it manufactures products under the brand of its retail chain. The company would like to declare and inspect all products for the possible presence of unwanted bodies in the content of its products. The simulation model clearly shows that performing such a control using the prior art would be highly inefficient. The proposal to streamline the process of such an inspection consists in locating a device that could detect any unwanted bodies in the products directly on the production line. It has been stated above that there is a sensor on the line that checks the correctness of printing the date of minimum consumption on the product packaging (Fig. 3, marked in yellow). In today's advanced period of existence of various sensors and detectors, it is possible to find on the market or custom manufacture a detector of similar shape and functionality for sensing metals, plastics, glass, wood, and similar substances, which could be present as a minimum consumption date sensor directly on the production line. The purpose of such a detector should be to detect every single product moving along the line. In case of any disagreement, notify the operator that there is something wrong with a particular product, or automatically remove this product from the line, without a lengthy interruption of production.

It would be appropriate to place such a sensor on the production line immediately after the classification named DS 2500, which performs the filling of cod into packaging, their closing and then marking the date of minimum consumption of products. Such a sensor (Fig. 10) would be supervised by the production operator, who would have the task of signalling a defective product to exclude such a product from the production process. In this way, $100 \%$ control of all products in the production process would be ensured and the quality of the entire production system would be increased. The company could then declare control of all its products to all customers in relation to the presence of undesirable substances and bodies in its products. This could, of course, also declare the complete health safety of its products in connection with a possible error in the production process, in which such undesirable bodies could enter the products. This would completely eliminate the health risk associated with the consumption of such a defective product for the end customer in absolutely all products offered by the company. The duration of such an inspection directly in the production process would be reduced to the time of scanning such a product, which would be about one second for each product. This would eliminate product handling and packaging times before and after the X-Ray detector. The products would be packaged only once and the finished products packed on pallets would proceed directly after production to the dispatch warehouse, thus increasing the efficiency and productivity of the entire production process. The application of such a device would also eliminate waste that may be unnecessarily generated in connection with the use of the X-ray detector, as each package of the product would be inspected separately. Should a discrepancy be found, the waste for the company would only be given the incorrect packaging of one product and not the whole packed carton with 16 pieces of products.

Another step to improve the productivity of a given production process would be to propose the use of a manipulator between the workplaces of cod packaging into cartons and palletizing of these cartons (Fig. 10). This step would relieve the burden of a worker who performed such packaging manually and placed each product individually in cartons on a pallet. This worker could move from the packaging position to a more comfortable and less strenuous position towards the Alien body detector and remove products that the detector would identify as faulty.

In the statistical indicators Fig. 11 shows how such a manipulator would affect the entire production run. The total productivity of the modelled production would increase to $47.16 \%$. Compared to the original state of production (Fig. 6), in which the inspection of unwanted parts in the products was not performed and the manipulation was performed manually by the worker, there was an increase of $1.1 \%$ of the total production. 


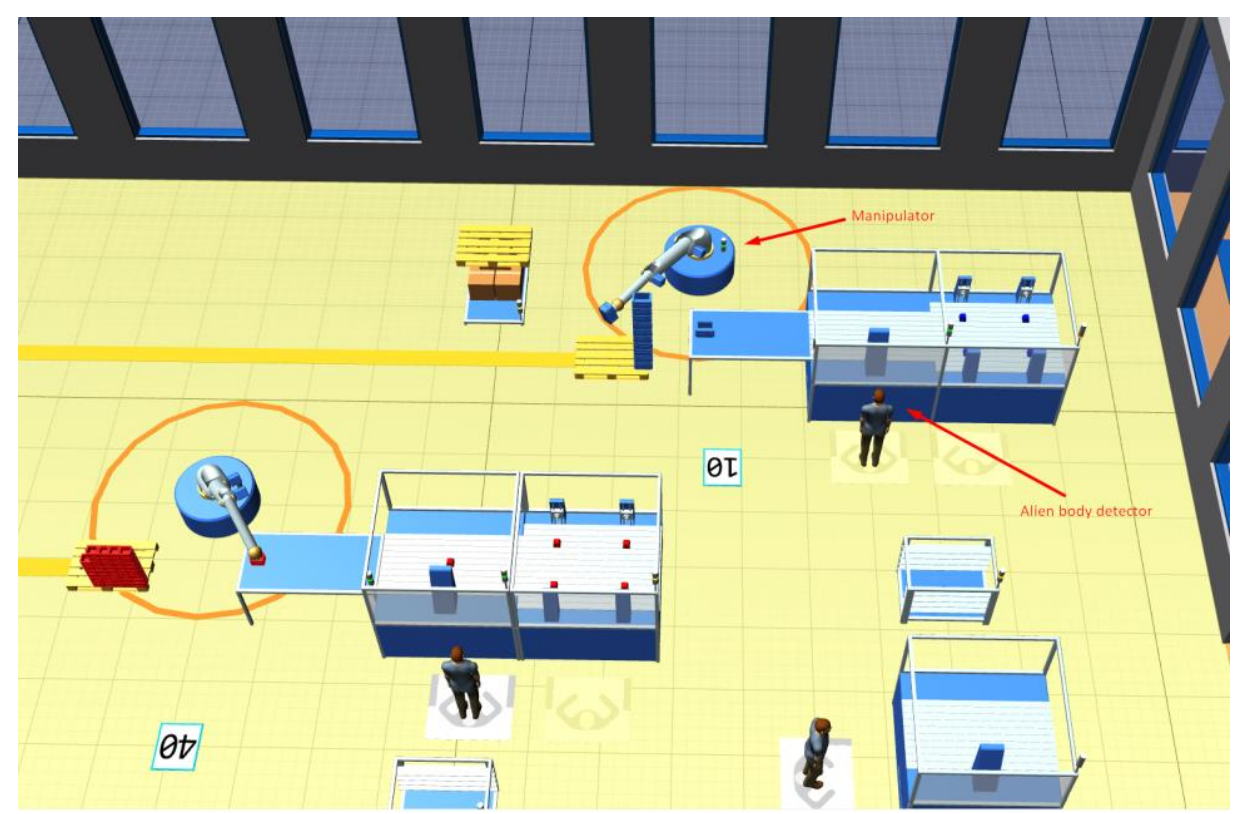

Figure 10: Design of Alien body detector implementation and manipulator during the packaging process.

\begin{tabular}{|c|c|c|c|c|c|c|c|c|c|}
\hline \multicolumn{10}{|c|}{ Cumulated Statistics of the Parts which the Drain Deleted } \\
\hline Object & Name & Mean Life Time & Throughput & $\mathrm{TPH}$ & Production & Transport & Storage & Value added & Portion \\
\hline End_of_production & Pallete_of_cod & $1: 25: 53.6496$ & 10 & 1 & $47.16 \%$ & $52.84 \%$ & $0.00 \%$ & $0.00 \%$ & 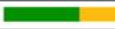 \\
\hline
\end{tabular}

\begin{tabular}{|l|r|r|r|r|l|}
\hline \multicolumn{1}{|c|}{ Object } & Working & Set-up & Waiting & Blocked & Portion \\
\hline Cod_decantation & $58.20 \%$ & $0.00 \%$ & $0.00 \%$ & $41.79 \%$ & \\
\hline Grinding_of_cod & $80.96 \%$ & $0.00 \%$ & $0.05 \%$ & $18.98 \%$ & \\
\hline Weighing_of_cod & $7.50 \%$ & $0.00 \%$ & $71.62 \%$ & $20.88 \%$ & \\
\hline Mixinf_of_cod & $18.62 \%$ & $0.00 \%$ & $10.83 \%$ & $70.56 \%$ & \\
\hline Cod_tray & $0.18 \%$ & $0.00 \%$ & $5.93 \%$ & $93.89 \%$ & \\
\hline DS_2500 & $26.30 \%$ & $0.00 \%$ & $47.29 \%$ & $26.42 \%$ & \\
\hline Alien_body_detector & $40.09 \%$ & $0.00 \%$ & $33.52 \%$ & $26.39 \%$ & \\
\hline Packaging_of_cod & $33.40 \%$ & $0.00 \%$ & $53.62 \%$ & $12.98 \%$ & \\
\hline manipulator & $32.63 \%$ & $0.00 \%$ & $50.69 \%$ & $16.68 \%$ & \\
\hline Palletizing_of_cod & $33.37 \%$ & $0.00 \%$ & $66.63 \%$ & $0.00 \%$ & \\
\hline
\end{tabular}

Figure 11: Statistical evaluation of the implementation of proposals for streamlining and increasing the quality of production using simulation.

\section{CONCLUSION AND OUTLOOK}

The whole paper is focused on the field of production systems and processes and points to the important role of simulation in increasing efficiency, productivity and optimization of production. The proposed implementation of a detector to detect the presence of unwanted alien bodies directly into the production system also increases the quality of products and the safety of the end consumer. The use of such equipment directly on the production line will significantly increase productivity, which is clearly visible in the statistical evaluation of individual production situations and outputs from the statistics of simulation software.

With the current method of production and control, productivity is at the level of $19.03 \%$. In the design of the use of the detector and the use of the manipulator in packaging, its level is $47.16 \%$, which is a significant increase. When comparing the current production system, which is used by regular customers, on which no control of unwanted parts is performed, the productivity of such production is at the level of $46.15 \%$. Even in this case, there is a visible improvement in the proposal compared to the original situation of $1.1 \%$. Such an increase may 
not seem very dizzying, and the question is what the return on such an investment would be for society. However, account must be taken of the fact that the simulation study was carried out on one product representative and states in the introduction that the manufacturing company has 400 products in its portfolio.

Most of these products are manufactured, or at least packaged in a similar way to Cod, which we have chosen as an example for creating such models. If a similar increase in productivity were confirmed for each product, the payback period of such investments would be significantly shortened. The determination of the amount of investment was not dealt with in this part, such a study is only an example for manufacturing companies carried out on real production. After studying it, it is up to the management of the company to deal with the amount and efficiency of such an investment.

The importance and applicability of simulation software and digitization processes in any area of industry is clearly visible in similar examples. Digitization of production processes and systems is important both for the automotive field and in other areas where the result of the transformation process is a product. Every production process can be constantly improved, and digitization will significantly shorten these processes. From a scientific point of view, the creation of such digital models is necessary, because when analysing different types of production systems, it is possible to create new model theories by applying new technologies. These theories can then be applied in other, for example, statistical analyses, which will be applicable in various other areas of life.

\section{ACKNOWLEDGEMENT}

This article was created by the implementation of the grant project APVV-17-0258 "Digital engineering elements application in innovation and optimization of production flows", APVV-19-0418 "Intelligent solutions to enhance business innovation capability in the process of transforming them into smart businesses", VEGA 1/0438/20 "Interaction of digital technologies to support software and hardware communication of the advanced production system platform" and KEGA 001TUKE-4/2020 "Modernizing Industrial Engineering education to Develop Existing Training Program Skills in a Specialized Laboratory".

\section{REFERENCES}

[1] Istokovic, D.; Perinic, M.; Dobovicek, S.; Bazina, T. (2019). Simulation framework for determining the order and size of the product batches in the flow shop: a case study, Advances in Production Engineering \& Management, Vol. 14, No. 2, 166-176, doi:10.14743/apem2019.2.319

[2] Prester, J.; Buchmeister, B.; Palčič, I. (2018). Effects of advanced manufacturing technologies on manufacturing company performance, Strojniski vestnik - Journal of Mechanical Engineering, Vol. 64, No. 12, 763-771, doi:10.5545/sv-jme.2018.5476

[3] Pekarcikova, M.; Trebuna, P.; Markovic, J. (2014). Case study of modelling the logistics chain in production, Procedia Engineering, Vol. 96 (Special issue: $6^{\text {th }}$ Conference on Modelling of Mechanical and Mechatronic Systems - MaMS), 355-361, doi:10.1016/j.proeng.2014.12.125

[4] Fusko, M.; Buckova, M.; Gaso, M.; Krajcovic, M.; Dulina, L.; Skokan, R. (2019). Concept of longterm sustainable intralogistics in plastic recycling factory, Sustainability, Vol. 11, No. 23, Paper 6750, 27 pages, doi: $10.3390 /$ su11236750

[5] Burieta, J. Simulation (Simulacia), from https://www.ipaslovakia.sk/clanok/simulacia, accesed on12-06-2020

[6] Fedorko, G.; Molnar, V.; Honus, S.; Neradilova, H.; Kampf, R. (2018). The application of simulation model of a milk run to identify the occurrence of failures, International Journal of Simulation Modelling, Vol. 17, No. 3, 444-457, doi:10.2507/IJSIMM17(3)440

[7] Bangsow, S. (2010). Manufacturing Simulation with Plant Simulation and SimTalk: Usage and programming with Examples and Solutions, Springer-Verlag, Berlin 
[8] Buckova, M.; Krajcovic, M.; Edl, M. (2017). Computer simulation and optimization of transport distances of order picking processes, Procedia Engineering, Vol. 192 (Special issue: 12 ${ }^{\text {th }}$ International Scientific Conference of Young Scientists on Sustainable, Modern and Safe Transport), 69-74, doi:10.1016/j.proeng.2017.06.012

[9] Micieta, B.; Edl, M.; Krajcovic, M.; Dulina, L.; Bubenik, P.; Durica, L.; Binasova, V. (2018). Delegate MASs for coordination and control of one-directional AGV systems: a proof-of-concept, International Journal of Advanced Manufacturing Technology, Vol. 94, 415-431, doi:10.1007/s00170-017-0915-8

[10] Gregor, M.; Hercko, J.; Grznar, P. (2015). The factory of the future production system research, Proceedings of the $201521^{\text {st }}$ International Conference on Automation and Computing (ICAC), 254-259, doi:10.1109/IConAC.2015.7313998

[11] Koblasa, F.; Śŕrová, E.; Králiková, R. (2019). The use of process thinking in the industrial practice - preliminary survey, Tehnicki vjesnik - Technical Gazette, Vol. 26, No. 3, 786-792, doi:10.17559/TV-20150617135306

[12] Wicher, P.; Stas, D.; Karkula, M.; Lenort, R.; Besta, P. (2015). A computer simulation-based analysis of supply chains resilience in industrial environment, Metalurgija, Vol. 54, No. 4, 703706

[13] Glova, J.; Sabol, T.; Vajda, V. (2014). Business models for the Internet of Things environment, Procedia Economics and Finance, Vol. 15 (Special issue: Emerging Markets Queries in Finance and Business - EMQ 2013), 1122-1129, doi:10.1016/S2212-5671(14)00566-8

[14] Laciak, M.; Raskayova, D.; Flegner, P.; Kacur, J.; Durdan, M. (2019). Automated system for optimizing input parameters of the UCG process, Proceedings of the $20^{\text {th }}$ International Carpathian Control Conference (ICCC), 311-315, doi:10.1109/CarpathianCC.2019.8765962

[15] Rosova, A. (2017). Methods and approaches to the evaluation of company performance, Poprad Economic and Management Forum 2017 (PEMF 2017), 31-36

[16] Laubertova, M.; Malindzakova, M.; Rosova, A.; Trpcevska, J. (2016). Material flow model of electronic waste sampling and assaying, Przemysl Chemiczny, Vol. 95, No. 7, 1390-1394, doi:10.15199/62.2016.7.23

[17] Saniuk, A.; Saniuk, S.; Caganova, D.; Cambal, M. (2014). Control of strategy realization in metallurgical production, Proceedings of the $23^{\text {rd }}$ International Conference on Metallurgy and Materials (METAL 2014), 1876-1881

[18] Patalas-Maliszewska, J.; Klos, S. (2019). An approach to supporting the selection of maintenance experts in the context of Industry 4.0, Applied Sciences, Vol. 9, No. 9, Paper 1848, 16 pages, doi:10.3390/app9091848

[19] Basl, J.; Sasiadek, M. (2017). Comparison of Industry 4.0 application rate in selected Polish and Czech companies, Proceedings of the Conference IDIMT-2017 - Digitalization in Management, Society and Economy, Schriftenreihe Informatik, Vol. 46, 401-410

[20] Marasova, D.; Saderova, J.; Ambrisko, L. (2020). Simulation of the use of the material handling equipment in the operation process, Open Engineering, Vol. 10, No. 1, 216-223, doi:10.1515/eng2020-0015

[21] Kotiadis, K.; Tako, A. A. (2018). Facilitated post-model coding in discrete event simulation (DES): a case study in healthcare, European Journal of Operational Research, Vol. 266, No. 3, 11201133, doi:10.1016/j.ejor.2017.10.047 